\title{
Influence of gender and locality on big five factors of personality and life satisfaction among elderly
}

\author{
Pragnya Priyadarshini Panda and V.S. Yadav
}

Received: 19.08.2019; Revised: 18.10.2019; Accepted: 02.11.2019

See end of the paper for authors' affiliations Pragnya Priyadarshini Panda Department of Human Development and Family Studies, College of Community Science, University of Agricultural Sciences, Dharwad (Karnataka) India Email : pandaguddi27@gmail. com
ABSTRACT : Old age is an age in which lot of changes occur with respect to physical changes, mental well-being and many more and there are so many factors naming the few like gender, locality, financial status and interpersonal relationships makes a difference in these changes. The present study was carried out to understand the differential effect of locality and gender on big five factors of personality and life satisfaction among elderly during 2016-17 in Dharwad taluk of Karnataka. The sample comprised 70 elderly; 35 elderlies from rural area and 35 elderlies from urban area (31 were male and 39 were female) in the age of 60 or above years. The background information of the elderly was collected with the help of self-structured questionnaire. Big five inventory was used to identify the big five factors of personality among elderly. Life satisfaction tool was used to measure life satisfaction among elderly. The results revealed that gender have not much impact on big five factors of personality and life satisfaction. But locality have greater impact on both the personality and life satisfaction. Elderly from rural area were distinctively better in big five factors of personality than urban area but elderly from urban area were better in life satisfaction compared to rural area.

KEY WORDS: Agreeableness, Conscientiousness, Emotional stability, Extraversion, Openness to experience, Life satisfaction

- HOW TO CITE THIS PAPER : Panda, Pragnya Priyadarshini and Yadav, V.S. (2019). Influence of gender and locality on big five factors of personality and life satisfaction among elderly. Asian J. Home Sci., 14 (2) : 341-346, DOI: 10.15740/HAS/AJHS/14.2/341-346. Copyright@ 2019: Hind Agri-Horticultural Society. 